\title{
Travestismo, homosexualidad y autoría queer durante el franquismo en Más bonita que ninguna (1965)
}

\section{Trabestismoa, homosexualitatea eta queer egiletza frankismoan, Más bonita que ninguna filmean (1965)}

\author{
Transvestism, homosexuality and queer \\ authorship during the francoist dictatorship \\ in Más bonita que ninguna (1965)
}

\section{Santiago Lomas Martínez ${ }^{1}$}

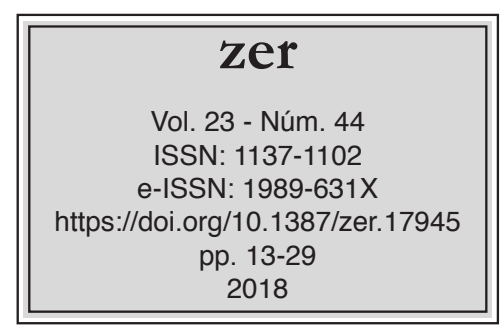

Recibido el 19 de junio de 2017, aceptado el 6 de noviembre de 2017.

\section{Resumen}

Durante el franquismo, la censura y la heteronormatividad social dificultaban la representación cinematográfica de disidencias de género y sexualidad. Frecuentemente, estas aparecían en contextos cómicos, flirteando con los límites de lo que podía expresarse públicamente en la época. En la comedia musical Más bonita que ninguna, el travestismo es protagonista de la narración y varios números musicales y genera numerosas tensiones textuales que aluden a la homosexualidad. Este artículo utiliza teoría fílmica queer para analizar las representaciones queer existentes en el filme y evidenciar las prácticas autorales queer de sus creadores, entre los que destaca el productor homosexual Luis Sanz.

Palabras clave: Franquismo; teoría queer; homosexualidad; historia del cine; cine español.

\section{Laburpena}

Frankismoan, zentsurak eta heteronormatibitate sozialak genero- eta sexualitate-disidentziak filmetan agertzea eragozten zuten. Askotan, testuinguru komikoetan agertzen ziren disidentzia horiek, garai hartan jendaurrean adieraz zitekeenaren mugekin jolasean. Más bonita que ninguna komedia musikalean, trabestismoa narrazioaren eta zenbait saio musikalen protagonista da, eta homosexualitatea zeharka aipatzen duten tentsio testual ugari sortzen ditu. Queer

${ }_{1}$ Universidad Carlos III de Madrid, slomas@hum.uc3m.es 
film-teoriaren bidez, artikulu honek filmeko queer adierazpenak aztertzen ditu, eta agerian jartzen ditu haren sortzaileen egiletza-jarduerak. Hain zuzen, sortzaileetako bat, Luis Sanz ekoizlea, homosexuala zen.

Gako-hitzak: Frankismoa; queer teoria; homosexualitatea; zinemaren historia; espainiar zinema.

\begin{abstract}
During the Francoist dictatorship, censorship and heterosocial heteronormativity hindered the filmic representation of gender and sexuality dissents. Frequently, these appeared in comic contexts, flirting with the limits of what could be publicly voiced at the time. Más bonita que ninguna is a musical comedy where transvestism is central to the narrative and some of its musical numbers, generating numerous textual tensions that allude to homosexuality. This article uses queer film theory to analyse the queer representations in the film and to highlight the queer authorship of its creators, among whom homosexual producer Luis Sanz stands out.

Keywords: Francoism; queer theory; homosexuality; film history; Spanish cinema.
\end{abstract}




\section{Introducción}

Durante las últimas décadas, la teoría queer ha permitido reconocer y estudiar el carácter múltiple, variable y diverso de la sexualidad humana y sus no menos variadas relaciones con el género, más allá de las tradicionales estructuras binarias hombre/masculino/heterosexual y mujer/femenina/heterosexual. Aplicada a los Estudios Fílmicos,

[los] usos de los términos 'lecturas queer', 'discursos queer' y 'posiciones queer' [...] son intentos de dar cuenta de la existencia y expresión de un amplio rango de posiciones dentro de la cultura que son 'queer' o no-, anti-, o contra-hetero. Uso el término 'queer' para marcar un espacio flexible para la expresión de todos los aspectos de producción y recepción cultural no-(anti-, contra-)hetero (Doty, 1993: 3) ${ }^{2}$.

Doty considera que cualquier texto fílmico puede contener elementos susceptibles de una lectura queer, alternativos al pensamiento esencialista basado en categorías de identidad de género y sexualidad claramente delimitadas, aceptado por la mayor parte de la sociedad. Incluso en textos creados por heterosexuales, es posible hallar potencialidades que pueden ser activadas y articuladas de forma queer por un lector dado (e incluso por grupos culturales). Así, "las lecturas queer surgen del reconocimiento y la articulación de la compleja gama de lo queer que ha existido en los textos de la cultura popular y sus audiencias todo el tiempo" (1993: 16).

Asimismo, en los últimos años, los estudios sobre cine español y homosexualidad han empezado a investigar en profundidad las películas realizadas durante el franquismo. Tradicionalmente, se ha asumido que, dada la existencia de censura y de una dictadura fuertemente heteronormativa, no hubo representaciones de homosexualidad en él, salvando unas pocas excepciones. Sin embargo, trabajos recientes han evidenciado la existencia de una gran pluralidad de representaciones, desmintiendo tales consideraciones convencionales (Melero, 2014, 2017). Según este autor, "la imposición de un silencio oficial y real no implicó la ausencia de discursos sobre homosexualidad, ni tampoco desde la homosexualidad [durante el franquismo....] ni uno solo de los grandes géneros y tendencias [de cine] obvió la cuestión de la homosexualidad" (2017: 16,24).

En este artículo, se realizará una lectura queer de Más bonita que ninguna (Luis César Amadori, 1965) para evidenciar cómo la utilización narrativa del travestismo permitía aflorar en el cine del franquismo -incluso en el más comercial-numerosas tensiones textuales queer, que evocan especialmente la homosexualidad, tanto masculina como femenina. Se trata de un caso singular en el cine del franquismo por presentar como protagonista a una mujer que pasa travestida gran parte del metraje.

La película presenta a Luisa (Rocío Dúrcal) y Roberto (Luigi Giuliani), una pareja que se miente mutuamente. Ella esconde que trabaja como tabaquera en El Molino Verde, un local de poca reputación donde hay actuaciones en vivo; él oculta que es un aristócrata arruinado que va a casarse con la hija de un rico empresario

Todas las traducciones son del autor. 
para mejorar su situación económica. Destrozada tras enterarse de la noticia, y al no tener un padre o hermano mayor que la defienda y haga valer su relación, Luisa decide hacerse pasar por hombre e inventa un hermano gemelo, Luisito. Ahora no solo exigirá a Roberto que sea responsable en su relación con ella, sino que, haciéndose pasar por su secretario, se entrometerá en su convivencia con la familia de su prometida, Delia, para tratar de boicotear su noviazgo. Mientras tanto, contará con la ayuda de su amiga Fanny (Gracita Morales), artista en El Molino Verde, donde Luisa deja de ser tabaquera para convertirse en una emergente artista que hace gala de su versatilidad como intérprete incorporando a sus actuaciones su recién descubierto talento para el travestismo. Así, logra el éxito en el local, tanto en su versión masculina como femenina, $y$, finalmente, tras conquistar a Roberto como pretendía, deja de interpretar a Luisito en su vida cotidiana.

El filme estaba concebido por el productor Luis Sanz como primer proyecto de su productora Cámara P.C., para proporcionar un vehículo de lucimiento a su protegida Rocío Dúrcal, con absoluto control creativo, tras años ejerciendo como productor sin acreditar en varios filmes de la productora Época Films para la estrella ${ }^{3}$. El guion fue realizado por Jesús María de Arozamena y Gabriel Peña (seudónimo del director, Amadori). En relación con ello, tras analizar los elementos representacionales queer del filme, se estudiará la autoría queer existente en él, evidenciando que tales elecciones creativas, que problematizaban las convenciones heteronormativas de su contexto histórico, podían ser operadas por creadores queer durante el franquismo.

Por tanto, en términos metodológicos, se hará una lectura queer del filme a partir de su análisis textual y de trabajos teóricos sobre la representación de la homosexualidad y el travestismo en el cine, continuando en el contexto nacional el legado de autores como Russo (1981), Dyer (1993) y Doty (1993, 2000), y, especialmente, el trabajo de Melero $(2014,2017)$, pionero en tratar de historizar exhaustivamente las representaciones de lo queer en el cine del franquismo. Todo ello se complementará con el análisis de la producción de la película, para el cual se han investigado los expedientes de censura tanto del guion como de la obra terminada, conservados en el Archivo General de la Administración (Alcalá de Henares), así como el guion del filme, disponible para consulta en la Biblioteca Nacional de España (Madrid). También se ha buscado información sobre sus creadores tanto en fuentes hemerográficas (los periódicos El País y $A B C$, principalmente) como bibliográficas (diccionarios sobre cine español, biografías, libros de memorias, entre otros). Por último, con el fin de determinar los posibles grados de autoría de los creadores de Más bonita que ningu$n a$, se han estudiado todas las películas producidas por Luis Sanz para Cámara P.C., tanto las protagonizadas por Rocío Dúrcal como las que no, así como las realizadas por el tándem creativo Amadori-Arozamena desde 1958, año en que Amadori dirigió su primer filme en España.

\section{El travestismo como herramienta evocadora del paradigma de inversión sexual}

En el cine del franquismo, el uso narrativo del travestismo permitía generar tensiones queer, poniendo en pantalla evocaciones y alusiones a la homosexualidad. El

Al respecto, véanse Riambau \& Torreiro (2008: 725) y Aguilar (2007: 15-78). 
travestismo, como operación performativa mediante la que una persona se presenta aparentemente como una persona de distinto sexo a su sexo biológico, problematizaba las tradicionales estructuras binarias hombre/masculino y mujer/femenina y, además, tenía fuertes vínculos con la conceptualización dominante de la homosexualidad en la época, basada en el paradigma de inversión sexual.

Este paradigma es uno de los discursos socioculturales y científicos más arraigados en Occidente para explicar la homosexualidad, y tuvo particular pujanza durante la primera mitad del siglo XX (Dyer, 1993: 31-39; Benshoff \& Griffin, 2006: 3-6, 21). El invertido, según la definición tradicional, es una persona de un sexo determinado (hombre o mujer), que manifiesta rasgos (físicos, psicológicos) del sexo contrario: puede tratarse de un hombre sumamente afeminado, o bien de una mujer sumamente masculinizada. Este discurso caló en la sociedad española y en sus autoridades médicas, y, ya en los años veinte y treinta, se consideraba invertido a aquel que manifestara su preferencia sexual por las personas de su mismo sexo, aunque con matices. Como han explicado Benshoff y Griffin, en las sociedades occidentales, con frecuencia, "solo las personas que se desviaban de su género esperado eran identificadas y etiquetadas como homosexuales" (2006: 21).

En el cine clásico occidental, fuera americano o europeo, los principales ejemplos de representación de personajes homosexuales vinieron dados con arreglo al paradigma de inversión sexual, consolidándose así dos estereotipos fundamentales: el del hombre afeminado o mariquita (sissy, pansy, queen) y la mujer masculinizada o marimacho (mannish woman, dyke) (Dyer, 1993: 31; Benshoff \& Griffin, 2006: 24-28). Durante el franquismo, se dio un uso frecuente de personajes queer como recursos humorísticos en el ámbito de la cultura (sobre todo, predominó el estereotipo del mariquita), y ello tiene como "explicación teórica [...] la concepción social que se tenía sobre cualquier desviación de la mayoría sexual”, según Melero (2014: 202), quien relaciona a este tipo de personajes con las figuras de los payasos y los bufones. A través de ellos, la sociedad convencional ha dado salida tradicionalmente a sus miedos y tabúes en situaciones de farsa y comicidad, y ha reído a costa de ellos. Dado el carácter social prohibido de la puesta en escena de conductas escandalosas o tabú, "todo se hace en un clima de flirteo con la transgresión que, no obstante, nunca sobrepasa los límites de lo socialmente aceptable" (2014: 203). La comedia era el marco ideal para acoger tales figuras y situaciones: estaba amparada a ojos de la sociedad y de los censores por su pretensión (aparentemente inocente) de hacer reír, que hacía tolerable cierto grado de subversión. Aun así, dado su potencial transgresor, los personajes queer solían ser limitados a apariciones puntuales en escenas concretas o bien intervenían como secundarios; es decir, podían funcionar como chistes esporádicos, o bien servían para añadir comicidad de manera más general a una comedia (2014: 200-204).

Ya en el cine de los años cuarenta, el travestismo logró hacerse algunos huecos que se mantendrían durante la dictadura, llegando en ocasiones a constituir representaciones más amplias y profundas, en términos narrativos y de duración en pantalla. El uso del travestismo como recurso cómico es descrito por Melero como un "primer paso hacia la revelación de una sexualidad desconcertante, [y] es la base de numerosas situaciones cómicas de películas de todo el franquismo, incluso algunas que no son comedias pero recurren a estas situaciones para crear escenas de distensión" (2014: 202). En tales situaciones, un personaje decide adoptar la apariencia de 
una persona del sexo opuesto, es decir, un hombre se viste y se comporta como una mujer, o viceversa. Las narrativas que incluían travestismo planteaban el tema de la homosexualidad de manera indirecta pues, como observan Benshoff y Griffin en el cine estadounidense, "cuando un hombre travestido flirtea con una mujer o es cortejado lascivamente por otro hombre, el espectro del deseo entre personas del mismo sexo está siempre presente, aunque solo sea para reírse a costa de él" (2006: 22). Por tanto, aunque casi siempre se diera en forma de apariciones cómicas o en el marco de comedias, el travestismo fue una de las principales estrategias para introducir elementos queer en el cine del franquismo, dado su potencial subversivo respecto a los imperativos heteronormativos del contexto: con él, y su supuesta finalidad cómica, se podía flirtear (y con bastante osadía, en ocasiones) con los márgenes de lo decible.

El travestismo de hombres fue más frecuente que el de mujeres. Melero ha encontrado mujeres travestidas en varias escenas de filmes tan tempranos como El pirata soy yo (José de Romero y Mario Mattoli, 1940) o Goyescas (Benito Perojo, 1942) y ha señalado que, si bien la comicidad era prácticamente inseparable de los travestismos de hombres, los de mujeres podían ser explotados con fines dramáticos:

"mientras que los hombres podían travestirse felizmente siempre dentro de un contexto de fiesta carnavalesca, las ocasiones para que una mujer se vistiese de hombre se limitaban al deseo o necesidad de ellas de acceder a encargos y profesiones vetados para las mujeres" (2017: 48).

Por otra parte, en comedias como La mini tía (Ignacio F. Iquino, 1968) o La viudita ye-yé (Juan Bosch, 1968, producida por Iquino), el travestismo de una mujer deriva hacia lo grotesco y hacia lo violento, tanto en términos narrativos (el travesti atrae a hombres que luego rechazan sus bigotes o barbas) como formales:

"En el mundo de Iquino, los travestis son desagradables, gritones y violentos, merecedores del castigo que les acaba por llegar. Esta violencia merecida es, también, parte del humor. La sobreactuación [...] contribuye a la creación del travesti como alguien desagradable, repudiado por su entorno" (2017: 229).

Más bonita que ninguna entronca con los primeros ejemplos porque presenta a una mujer que se traviste para adquirir agencia y poder, tradicionalmente reservados a los hombres. Sin embargo, se diferencia en que su protagonista se viste de hombre con el fin secreto de conquistar a otro: el travestismo se reencuadra, por tanto, en un marco de deseos y afectos ocultos por un hombre. Por otra parte, en la película, el travestismo se trata de forma amable, desprejuiciada y natural, como una actividad más que una chica podría realizar para enamorar a su amado: no hay, por consiguiente, ni derivas grotescas, ni violencia punitiva hacia el personaje travestido, transgresor de la normatividad social. Asimismo, Más bonita que ninguna se distingue de los ejemplos anteriores porque el travestismo no solo ocupa unas escenas, sino que la narrativa del filme gira en torno al travestismo y el protagonista es un personaje travestido. Es más, el personaje ficticio creado mediante el travestismo llega a tener más protagonismo, entidad propia e incluso resulta más carismático e interesante, en términos narrativos, que el personaje (convencionalmente) femenino que se decide a darle vida. 


\section{Aspectos queer relacionados con la homosexualidad en el filme}

Más bonita que ninguna evoca representacionalmente la homosexualidad masculina durante gran parte de su metraje. Desde el momento en que Luisa se traviste, visualmente, y para la mayoría de personajes, es Luisito, un muchacho de pelo corto, siempre vestido con traje gris formado por pantalones, chaqueta, camisa y corbata, que manifiesta un rol activo, descaro, vehemencia, e incluso agresividad: es capaz de encararse con Roberto, insinuando incluso estar dispuesto a llegar a las manos (lo cual sucede, hacia el final del filme, cuando le abofetea), o, como secretario de este, se enfrenta con su futuro suegro, un rico empresario, y desbarata sus planes de negocio. Caracterizado con estos elementos y rasgos tradicionalmente asociados a la masculinidad, Luisito resulta un hombre como los demás que, en realidad, oculta una identidad "femenina"4 . En términos representacionales, por tanto, Luisito remite al paradigma de inversión sexual, pues es un hombre que, psicológicamente, funciona como una mujer. Asimismo, al manifestar y estar motivado por un deseo secreto por otro hombre, la idea de la homosexualidad se evoca explícitamente: Luisito ama en secreto a Roberto, lo desea, y lo quiere para él solo, y, para conseguir sus objetivos, está dispuesto a destruir el inminente matrimonio de su amado con su novia concertada. En este sentido, dos escenas merecen ser destacadas particularmente por su osadía, pues, en ellas, Luisito verbaliza sus sentimientos por Roberto de forma abierta y clara.

El primero es el número musical "Mi corazón". Luisito canta con voz femenina, aparentemente a la novia de Roberto, pero, durante la canción, la aleja de este y la sienta con su primo Raúl (enamorado en secreto de ella), aproximándolos físicamente en una escalera y juntándoles las cabezas, como incitándoles a iniciar una relación entre sí. Mientras tanto, dirige su mirada (y, por tanto, el mensaje de su canción) a Roberto, y después, avanza por la estancia hasta colocarse frontalmente hacia donde está su amado. Con su posición espacial, mirada y gestos, delata que su canción de amor en realidad es para él, y el mensaje de dicha canción es claro: "Mi corazón / va volando, volando, volando, / y sé que a tu lado se tiene que parar. / [...] Me tienes, tienes, tienes que querer / que ya me enamorê".

Tras numerosos equívocos y enredos, el flirteo con la transgresión llega al extremo en la escena en la que Luisito se declara a Roberto. Ocurre hacia el final del filme: Roberto interroga a su secretario para saber por qué ha realizado toda una serie de acciones que considera perjudiciales para él:

Roberto: ¡Pero dime, insensato, delincuente juvenil! ¡¿Por qué has hecho todo esto?!

Luisito: ¡Por amor!

Roberto (Sorprendido): ¿Por amor a quién?

Luisito (Radiante): ¡A ti!

Roberto (Escandalizado): ¡Pero tú estás loco!

Luisito (Consciente de su transgresión): Es decir... ¡Estoy hablando en nombre de mi hermana!

\footnotetext{
${ }^{4}$ De hecho, en el guión, desde el momento en que la protagonista se traviste, y aun con sentimientos de mujer, es denominada Luisito y es tratada en masculino en todas las acotaciones.
} 
Con este diálogo, durante unos instantes, en un filme español de 1965, se ha conseguido representar lo más parecido posible a una declaración de amor homosexual. Tal transgresión de las convenciones heteronormativas logra verbalizarse en dicho contexto histórico, y de forma totalmente natural por parte del sujeto que enuncia su deseo por otro hombre. El conocimiento de que dicho sujeto es en realidad una mujer, y el rápido acto de desdecirse del personaje, cubren a los creadores del filme ante la censura y la sociedad homófoba, proporcionándoles la excusa de que lo que se ha visto era simplemente un enredo adicional derivado de la propia naturaleza del filme como comedia. Sin embargo, la enunciación ha tenido lugar, y, gracias a esa coartada, permanece en el filme cincuenta años después de su estreno.

Por otra parte, Más bonita que ninguna presenta también abundantes vínculos potenciales con el lesbianismo. Al ser Luisa una mujer que se viste y se comporta como un hombre, remite al paradigma de inversión sexual y a su principal estereotipo para representar lesbianismo, la mujer masculinizada o marimacho (Dyer, 1993: 31-37). En el cine español del franquismo, las vestimentas y los comportamientos masculinos fueron empleados como indicadores de lesbianismo (Melero, 2017: 160, $162,164)$. En la vida real, también muchas lesbianas decidieron adoptar una apariencia masculina ya desde la primera mitad del siglo $\mathrm{XX}^{5}$, $\mathrm{y}$, algunas, generaron en sus creaciones culturales imágenes lésbicas similares, como Stephen Gordon, la protagonista de la pionera novela lésbica The Well of Loneliness (Radclyffe Hall, 1928), la cual se considera un hombre con cuerpo de mujer. El potencial lésbico de la imagen de Rocío Dúrcal travestida se debe, por tanto, no solo a las representaciones estereotipadas de lesbianas en el cine, sino a la apropiación por parte de numerosas lesbianas de dicha visión del lesbianismo.

En Más bonita que ninguna, diversas frases y escenas presentan potencial lésbico más allá de la masculinidad de la apariencia y los comportamientos de Luisa cuando se hace pasar por Luisito. Al respecto, pueden destacarse los momentos en los que flirtea sutilmente con Delia, la prometida de Roberto, para provocar celos a este y propiciar así que la pareja se rompa. Por ejemplo, mientras todos pasan un fin de semana en la casa de campo del futuro suegro de Roberto, Luisa le dedica una canción, con su voz claramente femenina. Durante la canción, Luisa se acerca a Delia y la saca a bailar consigo, agarrándola de la cintura y pegándola a su cuerpo, llevando ella la iniciativa y marcando los movimientos.

Momentos similares pueden encontrarse en el número flamenco al final del filme, donde Rocío Dúrcal aparece vestida con traje típico andaluz de hombre (pantalones grises hasta la cintura, camisa y chaquetilla corta, con gorro echado a un lado de la cabeza). Mientras va cantando y zapateando, se aproxima a diversas bailarinas flamencas y actúa con ellas como un hombre en actitud de cortejo. No solo toma la iniciativa en sus movimientos hacia ellas, sino que (les) declara su deseo sexual y sus afectos por ellas: “¡Ay, eres bonita, / eres bonita! / ¡El conocimiento la pasión lo quita! / ¡Te quiero yo / más que a la madre que me parió!”. Durante la estrofa citada, enuncia el "te quiero yo" aproximándose a una hasta quedar a punto de darle un beso en la boca, para después separarse y bajar por una rampa llevando por la cintura a esta y a otra mujer, una agarrada con el brazo izquierdo y la otra con el derecho, con

\footnotetext{
5 Entre otras, cabe destacar a la escritora Radclyffe Hall, la pintora Romaine Brooks o la cineasta Dorothy Arzner (al respecto, véanse Dyer, 1993: 36-37 y Benshoff \& Griffin, 2006: 27).
} 
actitud segura y dominante, como un hombre que luciera en público sus dos conquistas femeninas.

El guion del filme preveía también un momento que (inexplicadamente) no se incluyó en la película: tras su primera actuación travestida en El Molino Verde, el público pedía un bis y, durante su interpretación, la protagonista bajaba del escenario e iba mesa por mesa sacando a bailar a cada una de las mujeres que se encontraban allí cenando, para después dejarlas con sus parejas masculinas e iniciar así un baile colectivo (Arozamena \& Amadori, 1965: 57-58). La escena, de enorme potencial queer, recuerda al célebre número musical de Marlene Dietrich en Morocco (Josef von Sternberg, 1930), donde la artista canta en una local vestida con esmoquin y chistera negros mientras se pasea entre los asistentes y flirtea con una mujer del público, se queda una flor que lleva puesta en el pelo y le roba un beso en la boca. Este momento, y el travestismo de Greta Garbo durante gran parte de Queen Christina (Rouben Mamoulian, 1933), así como el beso en la boca que esta propina a una secundaria, son dos instantes de gran popularidad en la cultura homosexual y además ejemplifican los límites representacionales del lesbianismo en Hollywood durante décadas, debido a la instauración en 1934 del Código Hays de censura (Dyer, 1993: 31-37; Benshoff \& Griffin, 2006: 26-27). En Más bonita que ninguna, no se llega al extremo del beso, pero todo lo demás sí tiene cabida.

Otra escena nos permite constatar la consciencia de los creadores del filme (Amadori, Arozamena, Sanz) acerca del potencial lésbico de lo que se estaba representando. Hacia la mitad del metraje, Luisito, ya secretario de Roberto, pasa una noche en el apartamento vacío de este con el criado que allí trabaja. Su amiga Fanny la visita y ambas se emborrachan, mientras Fanny se prueba un traje de Roberto y acaba travestida como Luisa, para extrañeza del criado. En contraste con su diversión, este aparece ocasionalmente en el salón donde ellas están, trayendo o llevando botellas y vasos. Después, Luisa y Fanny cantan y bailan travestidas, agitándose abrazadas mientras frotan sus mejillas. Justo entonces entra el criado, queda boquiabierto y reacciona hablándoles con enorme brusquedad, como rechazando lo que contempla. El guion preveía una réplica no incluida en el filme que acentúa aún más las connotaciones lésbicas de la escena: "Trae champán, que vamos a brindar por el amor, que flota en el aire...", ordena Fanny al criado (Arozamena \& Amadori, 1965: 121).

En la película, la escena termina con las dos amigas riéndose, aún travestidas, sentadas en un sofá. Sin embargo, en el guion, Arozamena y Amadori llevaban aún más lejos la situación y su potencial lésbico: tras cantar y bailar, las amigas deciden cambiarse de vestimenta y quedan en ropa interior. Luisa, agradecida a Fanny por haberle dejado el traje que utiliza para hacerse pasar por Luisito, abraza fuertemente a su amiga mientras la besa en cada mejilla. De nuevo, entra el criado en la habitación y queda asombrado: "Al ver el cuadro que se ofrece a su vista, en un movimiento instintivo deja caer la bandeja con todo su contenido y se pasa fuertemente la mano por la cara, como si quisiera ahuyentar una visión maléfica" (Arozamena \& Amadori, 1965: 122). La "visión" del criado no es otra que la de dos mujeres dándose afecto en paños menores, las cuales previamente han estado bailando con gran proximidad física vestidas como hombres. Las reacciones del criado ante cada nueva situación enfatizan que tales apariencias y comportamientos eran reconocidos como signos de homosexualidad en la época: precisamente, la comicidad de la escena dimana de 
que, lo que para Luisa y Fanny son solo comportamientos inocentes, para un espectador externo como el criado es en realidad algo muy (potencialmente) escandaloso.

\section{Autoría queer: colaboraciones creativas y diálogos con la (sub)cultura homosexual en Cámara P.C.}

Según Doty, lo queer puede tener origen en el ámbito de la creatividad:

Los creadores queer, incluyendo personas posicionadas [creativamente] como queers pero que se identifican con lo hetero ${ }^{6}$, entre bambalinas y delante de la cámara pueden ser también una fuente de lo queer que acaba en el producto final. Cómo de conscientes son estos productores queer sobre su papel en la codificación queer de textos de cultura popular es otra cuestión (2000: 4).

En otras palabras, lo queer de un texto fílmico puede estar producido por creadores queer, lo cual incluye también a personas heterosexuales en términos sexuales pero queer en términos creativos por el tipo de operaciones culturales que desarrollan, las cuales problematizan y/o desafían lo normativo en cuanto a género y sexualidad. En este sentido, la autoría queer de Más bonita que ninguna es fruto de la interacción de, fundamentalmente, dos creadores: en primer lugar, el productor Luis Sanz, homosexual, con unas constantes creativas marcadamente queer; y, en segundo lugar, el director y guionista Luis César Amadori, heterosexual, pero posicionado creativamente como queer (según la categoría establecida por Doty) al importar a España un modelo narrativo -también- marcadamente queer, proveniente de Argentina ${ }^{7}$.

Más bonita que ninguna es el primer filme producido por Sanz para su productora Cámara P.C. Representante de artistas desde 1951, descubrió y lanzó al estrellato a Rocío Dúrcal en 1962, produciéndole cuatro películas para la productora Época Films, donde no llegó a aparecer acreditado. En 1964, se independiza y funda la citada Cámara P.C., de la cual es consejero-delegado y principal accionista ${ }^{8}$. En sus filmes, Sanz ostentaba gran poder creativo, no solo como productor, sino como representante de los artistas a los que contrataba: entre sus representados, tuvo a muchas de las principales figuras del mundo artístico de los años cincuenta, sesenta y setenta: Dúrcal, Aurora Bautista, Lola Flores, Vicente Parra... y a directores como Amadori, Luis Lucia o Luis Saslavsky (Riambau \& Torreiro, 1998: 521). Los testimonios de las personas que trabajaron con él constatan su importante papel creativo sobre sus películas, sobre todo, en filmes como los realizados para Dúrcal, cuya formación como artista diseñó y supervisó personalmente y cuya evolución como estrella fue controlando en cada largometraje que produjo para ella ${ }^{9}$.

\footnotetext{
6 En el original, "queer-positioned, straight-identifying people".

7 Gracias a la Ley de Matrimonio Homosexual, Sanz llegaría a casarse con su compañero Francisco Belinchón. Amadori estaba casado con la actriz Zully Moreno, con quien tenía un hijo.

8 Para profundizar en la trayectoria de Sanz, puede consultarse Riambau y Torreiro (1998: 520-521; 2008: 725-727).

9 Sobre tales cuestiones, puede consultarse Aguilar (2007), donde Sanz es figura recurrente.
} 
Tras una primera etapa donde se explotó su imagen de adolescente, con Más bonita que ninguna, Sanz quiso cambiar la imagen de Dúrcal, tratando de dejar atrás su imagen de adolescente prodigio para enfatizar su versatilidad como actriz y, sobre todo, presentarla como más adulta (Aguilar, 2007: 81). Para esta nueva etapa artística, las elecciones creativas de Sanz como productor evidencian que toma como referente a la estrella femenina adulta más taquillera del momento (y principal icono de la subcultura homosexual española desde finales de los años cincuenta), Sara Montiel: contrata a su guionista habitual, Arozamena; al director que más veces había trabajado con ella tras su éxito en Él último cuplé (Juan de Orduña, 1957), Amadori; a su coreógrafo, Alberto Lorca; comparten diseñadores de vestuario como VargasOchagavía, letristas como Arozamena o Rafael de León y músicos como Juan Solano (estos dos últimos, también homosexuales);... en un proceso que culminará con la contratación del director de fotografía exclusivo de la diva, Christian Matras, para Las leandras (Eugenio Martín, 1969) ${ }^{10}$. Sanz, por tanto, controla a su estrella (Dúrcal) y a su director-guionista (Amadori) ejerciendo como su representante; selecciona al equipo técnico; decide cómo debe evolucionar la imagen de Dúrcal en ese momento de su carrera; y escoge que sea este filme, y no otro, su presentación oficial como productor con Cámara P.C. El artífice del proyecto es él, por tanto, y su labor creativa va más allá de la mera financiación de la producción.

En lo que respecta al director y guionista Amadori, resulta posicionado creativamente como queer porque importa a España un modelo narrativo marcadamente queer originario de Argentina, como él, que él mismo había contribuido a crear. Las diferencias de Más bonita que ninguna respecto a los usos del travestismo femenino en el cine franquista estudiados por Melero se deben a que su origen creativo es dicho modelo, estudiado por Peidro como "la comedia del cross-dressing femenino" (2015: 9-10). Dicho filón tiene como principales películas La estancia del gaucho Cruz (Leopoldo Torres Ríos, 1938), Luisito (Amadori, 1943), Vidalita (Luis Saslavsky, 1949) y La niña de fuego (Carlos Torres Ríos, 1952). Heredando el uso del travestismo femenino de la cultura del tango, estas comedias presentan mujeres protagonistas, cuyo travestismo les "permite [...] acceder a lugares que no podrían ocupar sin la vestimenta propia de los hombres" y "genera escenarios que desestabilizan la virilidad normativa y transgreden los compartimentos estancos del binarismo género-sexual" (13-14), "se abre una prometedora propuesta de desnaturalización de las identidades género-sexuales hegemónicas” (19). En ocasiones, el "cross-dressing funciona [...] por el deseo de algunos [hombres ...]. Así, [en Luisito,] Luisa decide disfrazarse de su supuesto hermano mellizo para recuperar el amor de Alberto. Liana, en La estancia del gaucho Cruz, también lo lleva a cabo para conquistar el amor del misógino Cruz" (14). Las estructuras heteronormativas, desestabilizadas y transgredidas durante el metraje, son restauradas en su desenlace, donde las mujeres travestidas recuperan su género tradicional (15-17); sin embargo, dicha heteronormatividad ha sido "también puesta en tensión con la relación homoerótica que se produce tanto entre Cruz y Samuel (La estancia del gaucho Cruz), entre Alberto y Luisito (Luisito), entre El capitán y Vidalita travestida (Vidalita) e incluso entre Fernando y Pocho, y Fernanda y la hermana de Pocho (La niña de fuego)" (17).

\footnotetext{
${ }^{10}$ Matras solo trabajó en España con Montiel, salvo alguna excepción puntual como Las leandras.
} 
Aunque no se reconozca en sus créditos, Más bonita que ninguna es, claramente, un remake de Luisito: tanto la narrativa como los nombres de sus personajes son prácticamente los mismos. Durante su estancia española, Amadori con frecuencia recicló contenidos de sus películas argentinas: por ejemplo, la narrativa de Caminito de gloria (1939) es reelaborada en Mi último tango (1960), o el final de Pecado de amor (1961) se parece enormemente al de Madreselva (1938). Dispuesto Amadori a reciclar, Sanz evidencia un posicionamiento creativo queer al elegir Luisito, y no otro proyecto, como su presentación oficial para él como productor y para su recién estrenada productora, Cámara P.C.

Peña ha caracterizado a Amadori como un cineasta comercial cuyas principales obsesiones temáticas son el dinero y el ascenso social $(2012$ : 72-73, 96):

\section{[...] nadie representó la idea de ascenso social mejor que Luis César Amadori [...] su tema principal es siempre el dinero [...], sea porque se busca, se gana, se guarda, se hereda o se sacrifica [...] Lo que le interesa es la posición [de los pudientes] y todo lo que sea necesario hacer para llegar a ella (2012: 72).}

Luisito y Más bonita que ninguna son coherentes con tales obsesiones: Luisa y Alberto/Roberto rompen porque él es un aristócrata arruinado que va a casarse por dinero; Luisito descubre que el suegro de Roberto quiere comprarle a bajo precio unas tierras que en realidad valen millones; Luisito logra hacer gestor del valioso patrimonio a Roberto; y, con el inicio de su relación, Luisa se beneficiará de ese dinero y del consiguiente ascenso social. En síntesis, el dinero y el ascenso social son elementos vertebradores de la narrativa del filme.

Sin embargo, lo interesante aquí es que los aspectos desestabilizadores de la heteronormatividad tradicional, que para Amadori no son prioridad creativa, serán apropiados y reelaborados por creadores homosexuales tras el estreno de Luisito en 1943: primero, Luis Saslavsky; luego, Sanz. El modelo narrativo introducido en el cine argentino por La estancia del gaucho Cruz y Luisito será reelaborado y llevado al extremo en Vidalita (1949), donde Saslavsky lo utiliza para jugar irónicamente con el imaginario nacionalista argentino relacionado con el criollismo, haciendo que sus personajes hablen en verso o que incluso al final haya una boda homosexual para muchos personajes (durante la boda de Vidalita y su amado capitán, muchos asistentes no saben que Vidalita es realmente una mujer). Mientras tanto, como en Más bonita que ninguna, se ha mostrado a un hombre aparente enamorado de otro hombre y, así, Saslavsky ha explorado los límites posibles de la representación de la homosexualidad en una fecha como 1949 (Bernini, 2008). Años después, Sanz se apropia del potencial queer de dichos filmes e importa sus convenciones a España, proponiendo que el travestismo de una mujer fuera el elemento central de una narrativa en un contexto donde este tipo de travestismos aparecían de forma puntual o secundaria, como ha estudiado Melero.

Las operaciones de Saslavsky y Sanz son vinculables con otras similares realizadas por creadores queer. Autores como Doty (1993: 35-38) o Benshoff y Griffin (2006: 54-55) han prestado particular atención a Sylvia Scarlett (1935), de George 
Cukor, donde la protagonista es una mujer que decide travestirse para huir junto a su padre de la policía, que ha descubierto los negocios turbios de este. Así, pasa gran parte del filme bajo apariencia masculina, haciéndose llamar Sylvester, y despertando el interés y la atracción tanto de mujeres como de hombres. Igualmente, puede destacarse el ejemplo de Lady Oscar (1979), de Jacques Demy, donde la protagonista es educada como un hombre y vive trabajando como soldado de los reyes Luis XVI y María Antonieta en el Palacio de Versalles (Duggan, 2013: 103-140). Asimismo, durante el franquismo, Juan de Orduña ya había flirteado con la representación de lo no heteronormativo incluyendo hombres travestidos en ;A mí la Legión! (1942), Tuvo la culpa Adán (1944), Música de ayer (1959) o Las golondrinas (1968) y una mujer travestida en La canción del olvido (1968), los tres últimos títulos con guiones de Arozamena.

En relación con este último detalle, puede agregarse que, aparte de Sanz, existen otros creadores queer en el filme. El citado guionista (y letrista) Arozamena era un hombre soltero y sin hijos ${ }^{11}$, que habitualmente trabajaba con homosexuales, cuyas creaciones están en constante diálogo con formas y tradiciones de la cultura homosexual, y que fue el responsable de numerosos guiones y canciones de tres de los principales iconos de la subcultura homosexual del franquismo: Sara Montiel, Luis Mariano y, en menor medida, Celia Gámez ${ }^{12}$. Actualmente, es difícil saber si Arozamena era o no homosexual, pero sí puede afirmarse que estaba posicionado creativamente como queer, según la definición de Doty: sus creaciones tenían un potencial queer que incluso era apropiado subculturalmente por muchos homosexuales durante el franquismo. Poniendo música a dos letras de Arozamena (Yo soy la vedette y Si yo tuviera rosas), figura Fernando Moraleda, compositor homosexual, uno de los grandes artífices de la revista musical española; encargado de la coreografía, aparece el bailarín Alberto Lorca (también soltero y sin hijos, pero con un "compañero" documentado) ${ }^{13}$; y, como autor de las letras Sombrero viejecito, Mi corazón y Más bonita que ninguna, está el enigmático Antonio Guijarro, letrista habitual del exitoso músico Augusto Algueró, del que apenas existen datos biográficos, salvo afirmaciones como las de la entonces esposa de Algueró, Carmen Sevilla: "Era un ser excepcional. Yo creo que ese chico era homosexual, pero antes no se sabía quién era homosexual... mariquita, vamos. [...] ¡Tenía una sensibilidad! Él hacía las letras, esas letras le salían de adentro a ese muchacho" (Herrera, 2005: 163-164).

Poco importa en qué categorías concretas de no-normatividad de género y/o sexualidad se podría clasificar a aquellos que no están documentados como normativamente heterosexuales: el hecho es que, en la productora Cámara P.C., se estaban dando colaboraciones creativas entre hombres queer durante el franquismo. Sin embargo, si bien autores como Tinkcom (1996) han estudiado grupos de trabajo queer en el contexto del Hollywood clásico como la Unidad Freed de la Metro Goldwyn Mayer, especializada en estilizados musicales, y otras como Duggan (2013) han analizado la dimensión queer del cine de Jacques Demy y las relaciones

\footnotetext{
${ }^{11}$ Así, al menos, consta en su esquela en El Diario Vasco (1 julio 1972).

${ }^{12}$ Según Moix, los iconos más admirados por los homosexuales españoles hacia finales del franquismo eran precisamente Sara Montiel, Celia Gámez, Raphael y Luis Mariano (1971: 6).

${ }^{13}$ Sobre la sexualidad de Moraleda, puede consultarse Ussía (2011); sobre Lorca, puede verse su esquela $(A B C, 13$ junio 2008).
} 
intertextuales y colaborativas de Demy con otros queers, ningún historiador ha prestado atención aún a Cámara P.C. y sus musicales. En los tres casos, el género musical sirve como bastión expresivo para dichos creadores en contextos sociales mayoritariamente heteronormativos.

Ciñéndonos al estudio de las prácticas creativas de Sanz como cineasta homosexual, puede decirse que estas están vinculadas con códigos, tradiciones y discursos de la subcultura homosexual de su contexto histórico. En otro artículo (2018), he estudiado a Sanz vinculándole con la tradición del creador homosexual y lo femenino, basada en la expresión cultural mediante códigos narrativos y estéticos vinculables con conceptualizaciones tradicionales de la feminidad (mujeres protagonistas, melodramas, musicales, estilización, énfasis en emoción...), y originada a finales del siglo XIX como vía de expresión homosexual dentro de la cultura dominante (Doty, 2000: 105-130). "Las películas de Sanz tienen como principal constante el protagonismo de estrellas femeninas [...]. El cineasta era especialista en diseñar vehículos de lucimiento para mujeres artistas", explicaba, agregando a continuación como segunda gran veta creativa "la recurrencia del género musical, una predilección que también puede leerse en términos subculturales" (2018, 69-70), pues el musical ha sido tradicionalmente muy apreciado entre el público homosexual, por permitir el lucimiento de grandes mujeres artistas y por presentar características estéticas convencionalmente consideradas femeninas o afeminadas, como exceso en color, vestuario o decorados; teatralidad; actuaciones intensas y enérgicas;..., entre otras (Doty, 1993: 10; Benshoff \& Griffin, 2006: 72-73). Más bonita que ninguna es, por tanto, coherente con las principales vetas creativas de Sanz como cineasta homosexual expuestas en dicho artículo. Asimismo, cabe añadir que, como productor, Sanz organiza su red de colaboradores queer en torno a dichos códigos y tradiciones.

El filme es vinculable con el uso tradicional de personajes femeninos por parte de cineastas homosexuales: con ellos, podían ubicar a un hombre como objeto de deseo en sus narrativas y hacerlas socialmente aceptables en contextos donde su expresión estaba limitada por la censura y/o la heteronormatividad imperante. Esta tradición creativa invierte los roles de género predominantes en el cine clásico (véase Mulvey, 1975): ubica como protagonistas a mujeres deseantes y convierte a los hombres en objetos deseados, y no al revés (Waugh, 1996: 109, 153). Más bonita que ninguna está en sintonía con dicha tradición: su narrativa reproduce esas dinámicas, al presentar a una mujer protagonista como sujeto deseante y a un hombre como objeto deseado. Es más, la condición de objeto de este queda reforzada por su enorme pasividad que contrasta con el carácter enormemente activo de Luisa. Curiosamente, el actor colocado como objeto de deseo es Luigi Giuliani, un fornido italiano de ojos azules, que se había dado a conocer en España interprendo al joven y problemático objeto de deseo de un maduro homosexual en L'isola di Arturo (Damiano Damiani, 1962), filme que sorprendió al público ganador del Festival de San Sebastián de 1962 por su tratamiento franco de la homosexualidad ${ }^{14}$. Casualidad o no, fue inmediatamente contratado como objeto de deseo del principal icono homosexual del periodo, Sara Montiel, en La reina del Chantecler (Rafael Gil, 1962), escrita por Arozamena a partir de una idea original del diseñador homosexual José Zamora. En otras palabras:

\footnotetext{
${ }^{14} \mathrm{Al}$ respecto, pueden verse informaciones de la época como Donald (1962).
} 
el hecho de que Sanz eligiera a Giuliani para ejercer de hombre objeto, tanto a nivel narrativo como a nivel estético, puede explicarse también en términos subculturales.

Por último, cabe destacar el potencial subcultural existente en el número musical final del filme, donde la protagonista canta y baila en clave folclórica vestida de hombre con traje típico andaluz. La hibridación de una apariencia masculina con un físico y una voz de mujer pone en pantalla la condición intersexual/inter-género del personaje, la cual es relacionable con toda una genealogía de cantantes folclóricos de marcado afeminamiento que desarrollaron sus carreras durante el franquismo. Dichos cantantes transgredían las convenciones de género y sexualidad exigidas a los hombres durante el periodo con indumentarias y gestualidad afeminadas: tales aspectos eran manifestaciones (voluntarias o no) de su identidad queer (casi siempre, homosexual), y, con frecuencia, funcionaban como indicios de ello a ojos de la sociedad. Es célebre el caso de Miguel de Molina, cantante de éxito durante la Segunda República, que, pocos años después de empezar la dictadura franquista, se exilió a Argentina. Sin embargo, también existieron otros artistas como Antonio Amaya, Pedrito Rico, Tomás de Antequera o Miguel de los Reyes. Como señalan García Piedra y Gil Siscar, todos ellos continuaron el legado de Miguel de Molina, apostando por vestirse con ropas llamativas (por sus colores o por incluir adornos vistosos como lentejuelas) y lucir -con grados variables de obviedad- gestos afeminados (2007: 59-63).

No resulta casual que el gran número final de Más bonita que ninguna sea este, y que surjan de forma potencial todas estas evocaciones. Sanz era un apasionado de la copla y el folclore andaluz, fue representante de muchas de sus estrellas e incluso productor musical de algunas. Su interés por la dimensión más queer de estas tradiciones musicales se manifestaría en recurrentes colaboraciones con dos de los máximos creadores de la copla, Rafael de León y Juan Solano, y, sobre todo, en sus películas Las cosas del querer (1989) y su secuela (1994), dirigidas por Jaime Chávarri, donde ejercería de productor, argumentista, guionista y director artístico, y crearía un personaje protagonista claramente inspirado en Miguel de Molina: Mario, un cantante folclórico homosexual que se ve obligado a exiliarse a inicios del franquismo y acaba desarrollando su carrera artística en Argentina. En este sentido, este número musical supone todo un antecedente, en términos artísticos y culturales, de los filmes citados.

\section{Conclusiones}

Más bonita que ninguna merece ser tenida en cuenta por la historiografía queer del cine español. En términos representacionales, destaca por la enorme duración en pantalla del travestismo de una mujer (que supera su aparición en una o varias escenas, lo habitual hasta entonces), la complejidad de su uso narrativo (que trasciende su utilización en la época como chiste puntual o trama cómica secundaria), así como la osadía en la presentación de un personaje que aparenta ser masculino, que esconde una identidad "femenina", desea en secreto a otro hombre, e incluso es capaz de declararse a él. Las formas mediante las que la película se aproxima a la representación de la homosexualidad (de, y entre, hombres y mujeres) en un contexto donde tales imágenes no gozaban de tanto protagonismo, duración y desarrollo 
narrativo la convierten en un singular hito en la historia queer del cine español. $\mathrm{Su}$ vocación comercial no impide la existencia de potencial disidente en términos de género y sexualidad (el cual no pasó desapercibido a la censura, que la prohibió para menores de 14 años, considerándola inapropiada -e incluso potencialmente perjudicial- para niños ${ }^{15}$ ).

Por otra parte, la película constituye la presentación oficial de uno de los cineastas homosexuales más prolíficos, poderosos, y, paradójicamente, menos estudiados del cine español, Luis Sanz. La dimensión queer de sus labores de producción se deriva de sus negociaciones creativas con códigos y tradiciones de la cultura homosexual, tanto a nivel transnacional como nacional. En primer lugar, bebe de la tradición del creador homosexual y la feminidad, tanto en términos narrativos como estéticos: en su larga relación profesional con su protegida Rocío Dúrcal, esta protagonizaría diversas narrativas de jóvenes enamoradas de hombres, escritas por cineastas posicionados creativamente como queers (Arozamena, Amadori) las cuales se inscribían en un género tradicionalmente conceptualizado como femenino, el musical, donde cantaba numerosas canciones que reflejaban dichas narrativas (compuestas, frecuentemente, por otros creadores queer, como Guijarro, Moraleda, León, Solano o, de nuevo, Arozamena). Como extensión de lo anterior, puede decirse que, en segundo lugar, lo queer se manifiesta en el cine de Sanz en sus colaboraciones creativas con otros queers (letristas, músicos, coreógrafos, diseñadores de vestuario...), por lo cual su obra puede estudiarse como resultado de una autoría queer colectiva y no solo individual. Ciñéndonos a Más bonita que ninguna, en tercer lugar, lo queer se manifiesta también mediante la apropiación y reelaboración de un modelo narrativo marcadamente queer, el de las narrativas protagonizadas por mujeres travestidas, que ya había sido utilizado por Saslavsky, y con el que tienen abundantes puntos en común otros usos del travestismo femenino por parte de otros creadores queer como Cukor u Orduña. Con dichas prácticas, estos cineastas pudieron explorar y jugar con los límites de la representación de disidencias de género y sexualidad en contextos donde la censura y/o la mayoritaria heteronormatividad social limitaban su expresión creativa. En cuarto lugar, resulta queer la elección como objeto de deseo del actor Luigi Giuliani, conocido en España por haber sido objeto de deseo cinematográfico de un personaje homosexual y de un icono homosexual. Por último, merece ser destacada la plasmación temprana de la fascinación de Sanz por la dimensión más queer del folclore musical hispano en el apoteósico número final de la película: dicho número permite la exhibición de los talentos artísticos de su protegida Dúrcal, pero también revela, en su primera película firmada tras años de profesión, gustos como persona y como creador que serán notablemente desarrollados en su carrera posterior.

\footnotetext{
${ }^{15}$ Informes de censura contenidos en la caja AGA,36,04150 del Archivo General de la Administración.
} 


\section{Referencias bibliográficas}

Aguilar, J. (2007). Rocío Dúrcal: volver a verte. Madrid: Nuevos Escritores.

Arozamena, J. M. y Amadori, L. C. (1965). Más bonita que ninguna [Guion]. Madrid: Imprenta Carmen Moreno.

Benshoff, H. M., y Griffin, S. (2006). Queer Images: A History of Gay and Lesbian Film in America. Lanham: Rowman \& Littlefield Publishers.

Bernini, E. (2008). Dos versiones del amor por los hombres. Sobre 'Vidalita' y 'Las ratas' de Luis Saslavsky. En A. Melo (Comp.), Otras historias de amor: gays, lesbianas y travestis en el cine argentino (pp. 67-75). Buenos Aires: Lea.

Donald. (1962). Italia: 'La isla de Arturo'. Francia: 'La denuncia'. ABC, 14 junio.

Doty, A. (1993). Making Things Perfectly Queer: Interpreting Mass Culture. Minneapolis: University of Minnesota Press.

Doty, A. (2000). Flaming Classics: Queering the Film Canon. New York: Routledge.

Duggan, A. E. (2013). Queer Enchantments: Gender, Sexuality, and Class in the Fairy-Tale Cinema of Jacques Demy. Detroit: Wayne State University Press.

Dyer, R. (1993). The Matter of Images: Essays of Representations. New York: Routledge.

García Piedra, J. C., y Gil Siscar, J. C. (2007). Lunares que entienden: márgenes eróticos de la copla española clásica. En J. Acebrón, y R. M. Mérida (eds.), Diálogos gays, lesbianos, queer (pp. 51-72). Lleida: Universidad de Lleida.

Herrera, C. (2005). Carmen Sevilla: memorias. Barcelona: Belacqva.

Lomas, S. (2018). Luis Sanz y 'Mi hijo no es lo que parece' (1973): subcultura homosexual y camp en el cine español del tardofranquismo. Journal of Spanish Cultural Studies, 19.1, 63-88.

Melero, A. (2014). La representación de la homosexualidad en el cine de la dictadura franquista. Zer: Revista de estudios de comunicación, 36, 189-204.

Melero, A. (2017). Violetas de España. Gays y lesbianas en el cine de Franco. Madrid: Notorious Ediciones.

Moix, T. (1971). Solo para amantes de mitos: Sara Montiel. Fotogramas, 1202, 5-9.

Mulvey, L. (1975). Visual Pleasure and Narrative Cinema. Screen, 16(3), 6-18.

Peidro, S. (2015). Configuración ideológica del travestismo en la ‘época de oro’ del cine argentino. Alter/nativas: Revista de estudios culturales latinoamericanos, 4, 1-24. Recuperado de http://alternativas.osu.edu/assets/files/Issue4/essays/peidro.pdf

Peña, F. M. (2012). Cien años de cine argentino. Buenos Aires: Biblos.

Riambau, E., y Torreiro, C. (1998). Guionistas en el cine español: quimeras, picarescas y pluriempleo. Madrid: Cátedra, Filmoteca Española.

Riambau, E., y Torreiro, C. (2008). Productores en el cine español: estado, dependencias y mercado. Madrid: Cátedra, Filmoteca Española.

Russo, V. (1981). The Celluloid Closet: Homosexuality in the Movies. New York: Harper \& Row.

Tinkcom, M. (1996). Working Like a Homosexual: Camp Visual Codes and the Labor of Gay Subjects in the MGM Freed Unit. Cinema Journal, 35(2), 24-42.

Ussía, A. (2011). Maricón. Tiempo, 3 junio. Recuperado de http://www.tiempodehoy.com/opinion/inactivos/alfonso-ussia/maricon

Waugh, T. (1996). Hard to Imagine: Gay Male Eroticism in Photography and Film From Their Beginnings to Stonewall. New York: Columbia University Press. 